\title{
Multiparametric ultrasound evaluation of a case of bilateral carotid body tumor
}

\author{
Patrizia Pacini $^{1} \cdot$ Giorgia Polti $^{1} \cdot$ Antongiulio Faggiano $^{2} \cdot$ Elisa Giannetta ${ }^{3} \cdot$ Maria Grazia Tarsitano $^{3} \cdot$ Vito Cantisani $^{1}$ (D)
}

Received: 17 March 2021 / Accepted: 23 March 2021 / Published online: 17 May 2021

(c) The Author(s) 2021

\begin{abstract}
Paragangliomas are a rare form of highly vascularized tumors that originate from paraganglia Baysal (J Med Genet 39: 617-622, 2002). In the head and neck PGL arise primarily in four distinct areas: vagal, middle ear, and larynx and more frequently carotid bifurcation. Imaging evaluations include sonography, color Doppler, US-elastosonography and contrastenhanced ultrasound (CEUS). Additionally, Computed Tomography, Magnetic Resonance Imaging (MRI) as well as digital subtraction angiography can be performed Stoeckli et al. (Laryngoscope 112: 143-146, 2002). We present herein a case of a rare bilateral carotid body tumor assessed with multiparametric ultrasound evaluation, including CEUS and US-elastography.
\end{abstract}

Keywords Paragangliomas $\cdot$ Head and neck $\cdot$ Carotid body tumors $\cdot$ Ultrasound $\cdot$ CEUS

\section{Introduction}

Head and neck paragangliomas (HNPGL) are a group of slow-growing hypervascular tumors associated with the paraganglion system [3], occurring at a rate of $0.03 \%$ of all tumors and $0.6 \%$ of all head and neck tumors. Radical surgery had been the traditional approach, but improvements in diagnostic imaging have opened new possibilities of nonsurgical therapy such as radiation therapy techniques in many patients or even medical therapy in selected cases [4]. HNPGLs most commonly represent a hereditary familial condition $[5,6]$. The predominant pathway involved in HNPGL tumorigenesis is the succinate dehydrogenase (SDH) enzyme, which is a multiprotein complex composed of SDHA, SDHB, SDHC, and SDHD proteins in addition to SDHAF2. PGLs arise from the paraganglia of the parasympathetic system in the $\mathrm{HN}$ and are rarely functional with an estimated prevalence of 1-9/1000 000 and the

Vito Cantisani

vito.cantisani@uniroma1.it

1 Department of Radiological, Pathological and Oncological Sciences, Sapienza University of Rome, 00161 Rome, Italy

2 Endocrinology Unit, Department of Clinical and Molecular Medicine, Sant'Andrea Hospital, Sapienza University of Rome, 00189 Rome, Italy

3 Department of Experimental Medicine, Sapienza University of Rome, 00161 Rome, Italy management is still not universally standardized. From a biological point of view, HNPGL are neuroendocrine tumors arising from paraganglia, slowly growing for the most but potentially locally invasive. After identification of the case index, a genetic screening is performed in all first-degree relatives. All carriers for SDH mutations need to undergo a clinical and radiological work-up. An, accurate and fast diagnosis is crucial for a prompt and reliable treatment of PGLs. The gold standard is the post-surgical histological exam, but several imaging modalities have been proposed for the workup of these patients, and among them, B-mode and color Doppler- sonography, uselastography and contrast-enhanced ultrasound (CEUS). Additionally, Computed Tomography (CT), Magnetic Resonance Imaging, 123I-Metaiodobenzylguanidine (MIBG) scintigraphy, PET-TC as well as digital subtraction angiography can be performed [2]. To the best of our knowledge, we present herein the second case of bilateral carotid body tumor studied with CEUS. Case presentation A 66 year-old Caucasian male presented to our observation with a painless, slowly growing swelling in the left lateral region, incidentally identified while shaving. The overlying skin was normal and there were no clinical signs referring to facial nerve injury. Patient's anamnesis did not reveal other oncological history or a similar case in his family. He came to our Radiology Department attention to perform a B-mode US evaluation as first-level assessment which showed: at Bmode a rounded lesion, with defined margins, with mixed echogenicity, approximately of $4 \mathrm{~cm}$, 


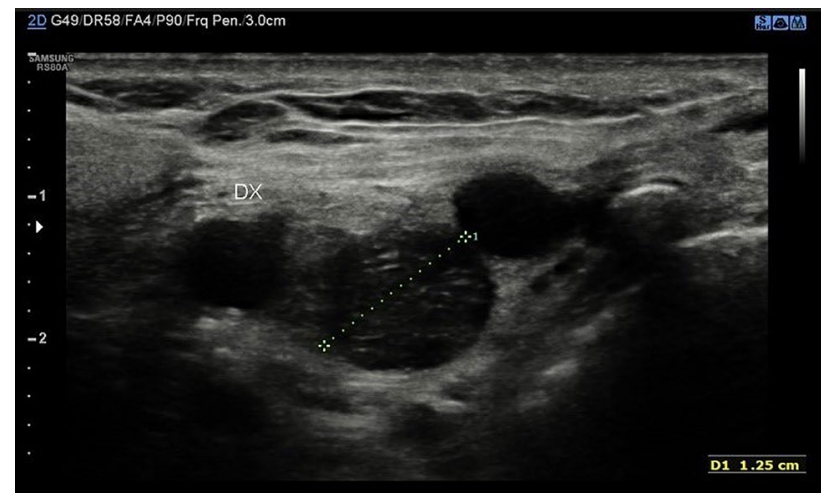

Fig. 1 Rounded mass with mixed echogenicity and defined margins, localized in the carotid bifurcation

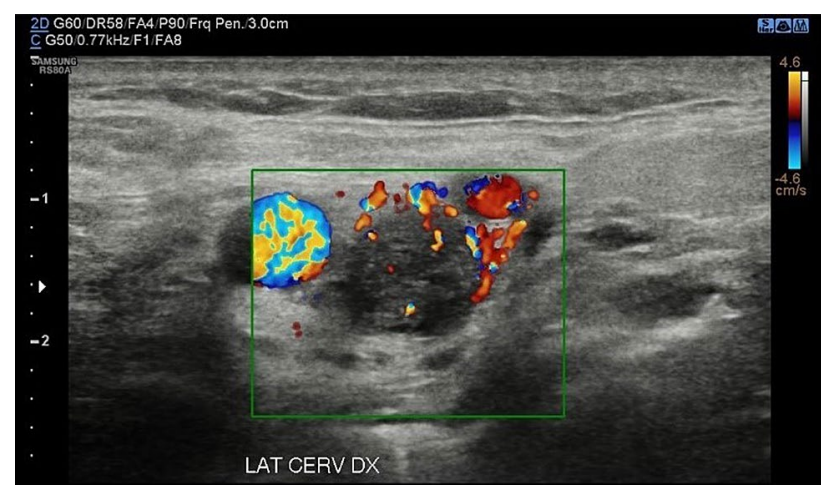

Fig. 2 A predominantly peripheral vascularization with some centripetal vessels at Color-doppler

localized in the carotid bifurcation (Fig. 1); color Doppler evaluation highlighted a predominantly peripheral vascularization with some centripetal vessels inside the lesion (Fig. 2). The patient subsequently was assessed by means of USE and the lesion appeared of hard consistency (Fig. 3); then at CEUS after administration $2 \mathrm{ml}$ of intravenous contrast medium (Sonovue, Bracco, Milan, Italy), followed by $10 \mathrm{ml}$ of isotonic saline solution the lesion presented homogeneous enhancement with enhancement similar to that of the internal carotid artery (Fig. 4), also confirmed at quantitative measurement using the Intensity-Time Curve (Fig. 5). Contralaterally, another smaller lesion with similar findings was identified. The final diagnosis of Glomus Carotid Paraganglioma was confirmed at post-surgical histology.

\section{Discussion and conclusions}

Familial paraganglioma syndrome type 1 (FPGL1) is due to mutation in SDHD gene and it is characterized by the development of PGLs, in the most of cases localized in head and neck region. PGLs normally present after the age of 30 years [7]. Clinical presentation of the CBT is an asymptomatic slowly growing mass in neck that usually identified by clinical examination or found incidentally on imaging studies; rarely the lesion can produce symptoms due to pressure and local invasion of the surrounding tissue. Clinical history, examination, and radiological diagnosis are the keystones to diagnosis and management. Multiparametric ultrasound with CEUS and USE, CT, MRI, and angiography play important roles in the clinical diagnosis of CBT. Color Doppler ultrasound, a simple and non-invasive examination, has relatively high specificity and sensitivity for CBT. Color-flow carotid duplex is the ideal screening test for CBTs, and these tumors are characteristically a well-defined hypoechoic mass that displaces the carotid bifurcation. With color Doppler imaging, a hypervascularity with low-resistance flow pattern is evident.

The most recent EFSUMB guideline describes USE [8] as a technique that requires mechanical or acoustic pressure on the organ of interest to measure the shear deformations
Fig. 3 At the US-elastography, the lesion appears stiff

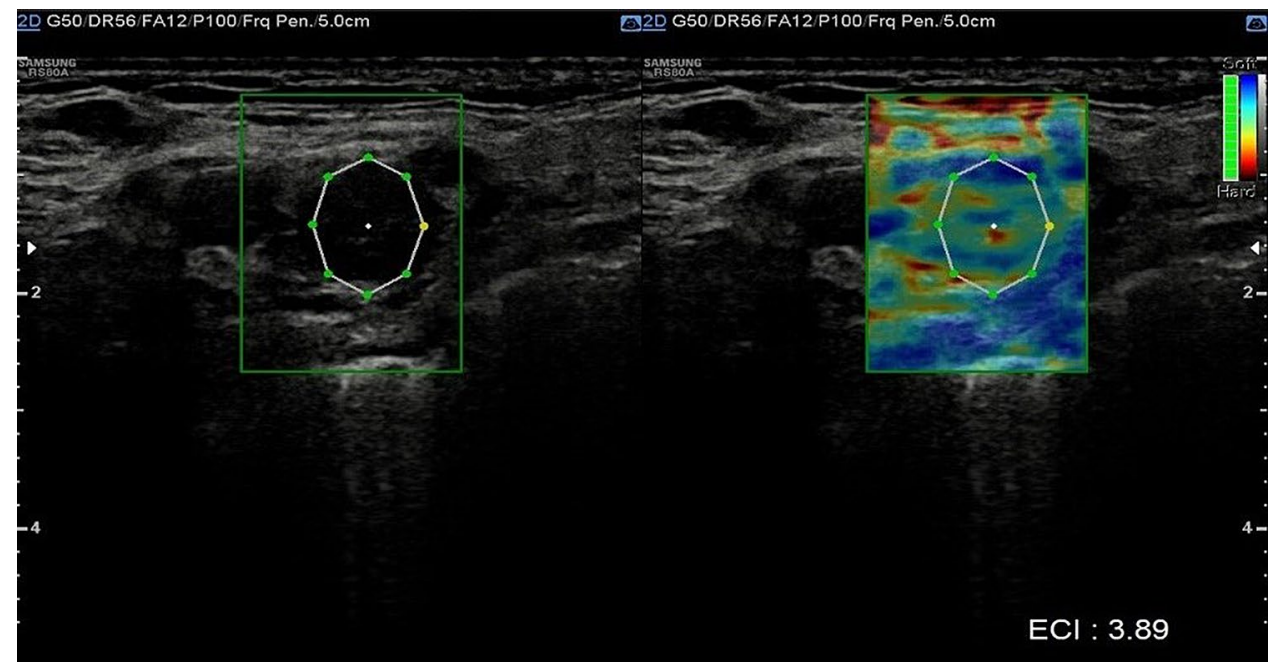


Fig. 4 CEUS examination revealed a homogeneous enhancement of the lesion with slow and progressive wash out as showed by Intensity-Time Curve in Fig. 5

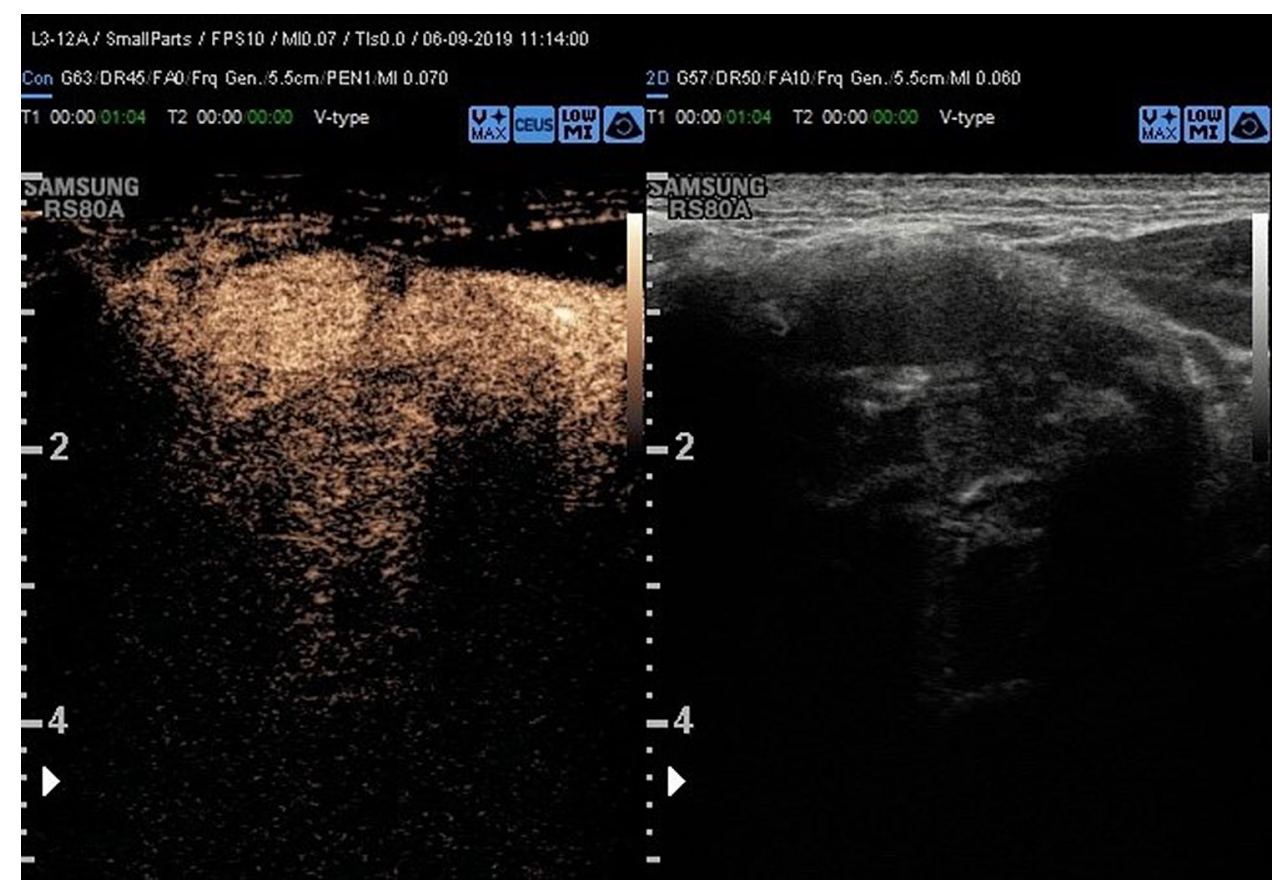

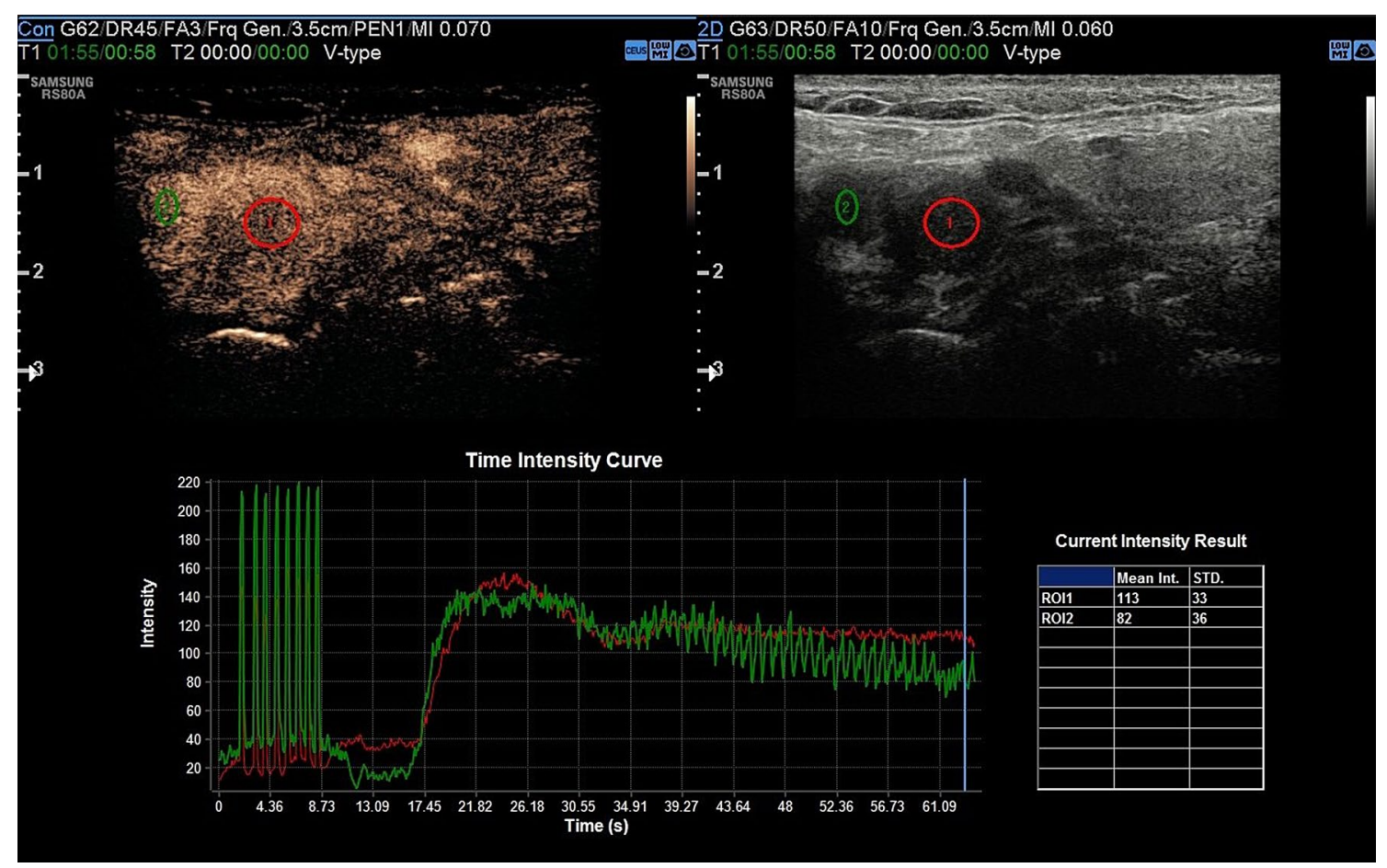

Fig. 5 Quantitative measurement using the Intensity-Time Curve

of the internal tissue resulting from this pressure. About the CBT there is not yet a clear and defined pattern the tumor it can be both soft and hard. In our case report the lesion appears of hard consistency.

Historically, angiography was the "gold standard" diagnostic procedure for CBTs to confirm the diagnosis and provide accurate delineation of the vascular supply. However, with improvements in high-resolution imaging, cross-sectional imaging (such as CT angiography or MR angiography) is the preferred modality for surgical planning of tumor resection because it best defines the relationship of the tumor with the artery bifurcation and the likely 
location of the cranial nerves. MRI does not use ionizing radiation, and the accuracy of MRI is higher in comparison to that of CT in many cases.

Although, CEUS has a recognized role for different organs [9-11]. There is still limited evidence on the use of CEUS in the head and neck paraganglioma $[12,13]$ and this is a second case of PGL published with CEUS and the first bilateral with multiparametric US. Our case has subtle differences from the further case of neck paraganglioma already described [12], presenting a mixed echogenicity at B-mode exam (versus hypoechogenicity), a predominantly peripheral vascularization with some centripetal vessels at the color Doppler evaluation (versus no vascularization in the middle) and a homogeneous enhancement similar to that of the internal carotid artery after administration of mdc.

Indeed, CEUS appears a useful and safe tool for identifying CBTs and evaluating intratumoral microperfusion at high spatial and temporal resolutions in real-time, although it should be taken in account the main limitation that is the lack of panoramicity. In the daily clinical routine CEUS can be used to easily monitor therapy success and efficiency after embolization and seems to be a viable option with superior benefits compared to standard Color-Doppler for follow-up of these patients. Additionally, CEUS can be performed on almost every patient because of the limited contraindications of the used contrast agent. Patients with reduced renal function can particularly benefit from this method [11]. In the recent guidelines published in Ultraschall on the CEUS use for non-hepatic applications, it has been reported that nneuroendocrine tumors typically present as hyper-enhancing lesions in the arterial phase of CEUS examinations, owing to their significant arterialization and that based on the ENETs Consensus Guidelines, CEUS has been suggested as an imaging modality for the diagnosis of neuroendocrine neoplasms[10]

In conclusion CEUS may be implemented in the future diagnostic work-up and follow-up of CBT patients in addition to conventional ultrasound, CT, MRI and digital substraction angiography (DSA). Therefore, further multi-center studies are encouraged to confirm the clinical use of these techniques on CBTs, as limited evidence is still available.

Funding Open access funding provided by Università degli Studi di Roma La Sapienza within the CRUI-CARE Agreement. None.

\section{Declarations}

\section{Conflict of interest None.}

Ethical statements All procedures followed were in accordance with the ethical standards of the responsible committee on human experi- mentation (institutional and national) and with the Helsinki Declaration of 1975 , as revised in 2000 .

Infomed consent Duly signed informed consent was taken from the patient in question to include personal case details and clinical images. Confidentiality was ensured at all stages.

Open Access This article is licensed under a Creative Commons Attribution 4.0 International License, which permits use, sharing, adaptation, distribution and reproduction in any medium or format, as long as you give appropriate credit to the original author(s) and the source, provide a link to the Creative Commons licence, and indicate if changes were made. The images or other third party material in this article are included in the article's Creative Commons licence, unless indicated otherwise in a credit line to the material. If material is not included in the article's Creative Commons licence and your intended use is not permitted by statutory regulation or exceeds the permitted use, you will need to obtain permission directly from the copyright holder. To view a copy of this licence, visit http://creativecommons.org/licenses/by/4.0/.

\section{References:}

1. Baysal BE (2002) Hereditary paraganglioma targets diverse paraganglia. J Med Genet 39(9):617-622. https://doi.org/10.1136/jmg. 39.9.617

2. Stoeckli SJ, Schuknecht B, Alkadhi H, Fisch U (2002) Evaluation of paragangliomas presenting as a cervical mass on color-coded Doppler sonography. Laryngoscope. 112(1):143-146. https://doi. org/10.1097/00005537-200201000-00025

3. Moore MG, Netterville JL, Mendenhall WM, Isaacson B, Nussenbaum B (2016) Head and neck paragangliomas: an update on evaluation and management. Otolaryngol Head Neck Surg 154(4):597-605. https://doi.org/10.1177/0194599815627667

4. Lee JH, Barich F, Karnell LH, Robinson RA, Zhen WK, Gantz BJ, Hoffman HT (2002) American College of Surgeons Commission on Cancer; AmericanCancer Society. National Cancer Data Base report on malignant paragangliomas of the head and neck. Cancer 94(3):730-737. https://doi.org/10.1002/cncr.10252

5. Castro-Vega LJ, Letouzé E, Burnichon N, Buffet A, Disderot PH, Khalifa E, Loriot C, Elarouci N, Morin A, Menara M, LepoutreLussey C, Badoual C, Sibony M, Dousset B, Libé R, Zinzindohoue F, Plouin PF, Bertherat J, Amar L, de Reyniès A, Favier J, Gimenez-Roqueplo AP (2015) Multi-omics analysis defines core genomic alterations in pheochromocytomas and paragangliomas. Nat Commun 27(6):6044. https://doi.org/10.1038/ncomms7044. PMID:25625332;PMCID:PMC4354166

6. Dahia PL (2014) Pheochromocytoma and paraganglioma pathogenesis: learning from genetic heterogeneity. Nat Rev Cancer 14(2):108-119. https://doi.org/10.1038/nrc3648 (PMID: 24442145)

7. Neumann HP, Pawlu C, Peczkowska M, Bausch B, McWhinney SR, Muresan M, Buchta M, Franke G, Klisch J, Bley TA et al (2004) Distinct clinical features of paraganglioma syndromes associated with SDHB and SDHD gene mutations. JAMA 292:943-951. https://doi.org/10.1001/jama.292.8.943

8. Săftoiu A, Gilja OH, Sidhu PS, Dietrich CF, Cantisani V, Amy D, Bachmann-Nielsen M, Bob F, Bojunga J, Brock M, Calliada F, Clevert DA, Correas JM, D'Onofrio M, Ewertsen C, Farrokh A, Fodor D, Fusaroli P, Havre RF, Hocke M, Ignee A, Jenssen C, Klauser AS, Kollmann C, Radzina M, Ramnarine KV, Sconfienza LM, Solomon C, Sporea I, Ștefănescu H, Tanter M, Vilmann P (2019) The EFSUMB guidelines and recommendations for the 
clinical practice of elastography in non-hepatic applications: update 2018. Ultraschall Med 40(4):425-453. https://doi.org/10. 1055/a-0838-9937

9. Ricci P, Laghi A, Cantisani V, Paolantonio P, Pacella S, Pagliara E, Arduini F, Pasqualini V, Trippa F, Filpo M, Passariello R (2005) Contrast-enhanced sonography with SonoVue: enhancement patterns of benign focal liver lesions and correlation with dynamic gadobenate dimeglumine-enhanced MRI. AJR Am J Roentgenol 184(3):821-827. https://doi.org/10.2214/ajr.184.3. 01840821 (PMID: 15728603)

10. Sidhu PS, Cantisani V, Dietrich CF, Gilja OH, Saftoiu A, Bartels E, Bertolotto M, Calliada F, Clevert DA, Cosgrove D, Deganello A, D'Onofrio M, Drudi FM, Freeman S, Harvey C, Jenssen C, Jung EM, Klauser AS, Lassau N, Meloni MF, Leen E, Nicolau C, Nolsoe C, Piscaglia F, Prada F, Prosch H, Radzina M, Savelli L, Weskott HP, Wijkstra H (2018) The EFSUMB guidelines and recommendations for the clinical practice of contrast-enhanced ultrasound (CEUS) in non-hepatic applications: update 2017 (short version). Ultraschall Med 39(2):154-180. https://doi.org/ 10.1055/s-0044-101254 (PMID: 29510440)

11. Dietrich CF, Nolsøe CP, Barr RG, Berzigotti A, Burns PN, Cantisani V, Chammas MC, Chaubal N, Choi BI, Clevert DA, Cui X, Dong Y, D’Onofrio M, Fowlkes JB, Gilja OH, Huang P, Ignee A, Jenssen C, Kono Y, Kudo M, Lassau N, Lee WJ, Lee JY, Liang P, Lim A, Lyshchik A, Meloni MF, Correas JM, Minami Y,
Moriyasu F, Nicolau C, Piscaglia F, Saftoiu A, Sidhu PS, Sporea I, Torzilli G, Xie X, Zheng R (2020) Guidelines and good clinical practice recommendations for contrast-enhanced ultrasound (CEUS) in the Liver-Update 2020 WFUMB in cooperation with EFSUMB, AFSUMB, AIUM, and FLAUS. Ultrasound Med Biol 46(10):2579-2604. https://doi.org/10.1016/j.ultrasmedbio.2020. 04.030 (PMID: 32713788)

12. Rübenthaler J, Lutz J, Reiser M, Clevert DA (2015) Titelbildbeitrag - Paragangliome des Kopfes und des Halses: Follow-Up von Interventionen mittels kontrast-verstärkter Sonographie (CEUS). Ultraschall Med 36(6):541-543. https://doi.org/10.1055/s-00351552392 (PMID: 26841712)

13. Puliani G, Sesti F, Feola T, Di Leo N, Polti G, Verrico M, Modica R, Colao A, Lenzi A, Isidori AM, Cantisani V, Giannetta E, Faggiano A (2020) Natural history and management of familial paraganglioma syndrome type 1: long-term data from a large family. J Clin Med 9(2):588. https://doi.org/10.3390/jem9020588 (PMID:32098148; PMCID:PMC7074269)

Publisher's Note Springer Nature remains neutral with regard to jurisdictional claims in published maps and institutional affiliations. 